\title{
A TRIBUTAÇÃO SOBRE O CONSUMO EM FACE DA TEORIA CONSTITUCIONAL BRASILEIRA: UM CORTE HISTÓRICO SOBRE SUA DOGMATIZAÇÃO IMPOSITIVA
}

\author{
Antônio Carlos Diniz Murta ${ }^{1}$ \\ Luisa Mendonça Albergaria de Carvalho
}

\begin{abstract}
Resumo: A busca de tributos é essencial para manter a estrutura do estado. Entretanto, cada vez mais aferem-se distorções seja na quantidade seja no seu enfoque. A tributação brasileira é estruturada no consumo, este tributado em todos os níveis federativos. Buscou-se uma exposição perfunctória sobre a evolução da tributação para delinearmos, mesmo que de forma ainda incipiente, um quadrante histórico da tributação sobre o consumo brasileiro, não deixando de abordar os conceitos e características desta incidência, em seu aspecto geral e jurídico, relacionando, quando possível, com o atual cenário de crise fiscal vivida no país.
\end{abstract}

Palavras - chave: História da tributação no Brasil; evolução histórica sobre a tributação sobre o consumo; reforma fiscal.

1 Graduação em Direito pela Faculdade de Direito da Universidade Federal de Minas Gerais (1987). Especialização em Direito Comercial pela Faculdade de Direito da Universidade Federal de Minas Gerais (1994). Doutorado em Direito Comercial pela Faculdade de Direito da Universidade Federal de Minas Gerais (2000). Procurador do Estado, lotado na Procuradoria de Tributos e Finanças de MG (PTF), órgão integrante da Advocacia Geral do Estado de Minas Gerais (AGE/MG). Coordenador da Procuradoria de Tributos e Finanças (PTF), da Advocacia Geral do Estado de Minas Gerais (AGE/MG), junto ao Conselho de Contribuintes de Minas Gerais (CC/MG). Membro da Comissão Permanente de Revisão e Simplificação da Legislação Tributária do Estado de Minas Gerais, no âmbito da Secretaria da Casa Civil e Relações Institucionais e da Secretaria de Estado da Fazenda. Presidente do Conselho de Curadores da Fundação Mineira de Educação e Cultura / Universidade FUMEC. Professor Titular da Faculdade de Ciências Humanas, Sociais e da Saúde (FCH), unidade integrante da Fundação Mineira de Educação e Cultura / Universidade FUMEC. Editor Adjunto da Revista de direito tributário e financeiro. Membro da Congregação da Faculdade de Ciências Humanas, Sociais e da Saúde (FCH), unidade integrante da Fundação Mineira de Educação e Cultura/ Universidade FUMEC. Integrante do Núcleo Referencial Docente (NRD), do Curso de Direito, da Faculdade de Ciências Humanas, Sociais e da Saúde $(\mathrm{FCH})$, unidade da Fundação Mineira de Educação e Cultura/ Universidade FUMEC. Membro/Conselheiro do Conselho de Curadores da Fundação Mineira de Educação e Cultura/Universidade FUMEC. Avaliador institucional e de curso de Graduação de Direito, do Instituto Nacional de Estudos e Pesquisas Educacionais Anísio Teixeira (INEP), órgão educacional integrante da diretoria de Avaliação de Educação Superior (DAES), órgão integrante do Ministério da Educação (MEC). Avaliador - Brazilian Journal Of Law/Revista de Direito Brasileira - Conselho Nacional de Pesquisa e Pós- Graduação em Direito/CONPEDI. Avaliador da Escola Superior Dom Helder Câmara, conselheiro de avaliação da Escola Superior Dom Helder Câmara, Associado da Associação dos Diplomados da Escola Superior de Guerra (ADESG). Tem experiência na área de Direito, com ênfase em Direito, atuando principalmente nos seguintes temas: direito tributário, avaliação curso de direito, pós-graduação em Direito, parecer agência fomento, direito administrativo e tributação. Coordenador de projeto de pesquisa / demanda universal da Fundação de Amparo à Pesquisa de Minas Gerais / FAPEMIG. Membro da Secretaria de Eventos do Conselho Nacional de Pesquisas e Pós-Graduação em Direito / CONPEDI.

2 Advogada. Possui graduação em Direito pela Universidade FUMEC (2011); Pós graduação em Direito Tributário pela Newton Paiva (2014); Pós graduação em Processo Penal pela Faculdade Arnaldo (2015); Mestrado em Direito Público pela Universidade FUMEC(2017); Bolsista de projeto de pesquisa / demanda universal da Fundação de Amparo à Pesquisa de Minas Gerais / FAPEMIG; Redatora de artigos tributários semanais no site Gotributario; Rede Social com vídeo-aulas @ tribufacilbh. Endereço de email: albergariaadvocacia@gmail.com.

Revista Brasileira de Teoria Constitucional | e-ISSN: 2526-0251 | Porto Alegre | v. 4 | n. 2 | p. 22 - 43 | Jul/Dez. 2018 


\title{
THE TAX ON CONSUMPTION IN THE FACE OF THE BRAZILIAN CONSTITUCIONAL THEORY: A HISTORICAL CUT ON ITS TAX DOGMATIZATON
}

\begin{abstract}
The pursuit of taxes is essential to maintain the structure of the state. However, distortions are increasing in both quantity and focus. Brazilian taxation is structured into consumption, which is taxed at all federative levels. We sought a perfunctory exposition on the evolution of taxation in order to delineate, even if still incipient, a historical quadrant of taxation on Brazilian consumption, while noting the concepts and characteristics of this incidence, in its general and legal aspect, relating, when possible, with the current scenario of fiscal crisis experienced in the country.
\end{abstract}

Key-words: History of taxation in Brazil; historical evolution on taxation on consumption; tax reform.

\section{INTRODUÇÃO}

O Brasil esta vivendo um período em que se clama pela necessidade de se repensar a tributação em face da imprescindibilidade de se instituir uma política administrativa, contínua e sustentável, de desenvolvimento econômico e social, equilibrando a ordem fiscal e sua contrapartida social.

De acordo com Odilon Guedes (2016), o que o Brasil precisa, para avançar na superação da crise fiscal, é do desenvolvimento de ponderações sobre alternativas que visem dar maior racionalidade ao sistema tributário vigente, favorecendo com isso o setor produtivo, a distribuição de renda e estimulando a recuperação da capacidade de investimento do Estado.

O Sindicato dos Economistas no Estado de São Paulo elaborou uma proposta de Reforma Tributária ${ }^{3}$ para ser debatida e que até o momento têm obtido apoio significativo da nossa sociedade.

Resumidamente os pontos centrais dessa proposta são os seguintes:

1. Diminuição dos tributos indiretos o que favorecerá as empresas diminuindo seus custos de produção, que deverá ser repassado para os preços. Isso aumentará

\footnotetext{
3 Transparência fiscal impulsiona reforma tributária: No começo de 2015, entrou em vigor a lei $n^{\circ}$ 12.741/2012 "De Olho no Imposto" que estabeleceu, a todas as empresas que comercializam produtos ou serviços, a obrigatoriedade da transparência fiscal, ou seja, todos os tributos incidentes sobre mercadorias ou serviços devem estar claras ao consumidor final e constar na nota fiscal.
} 
indiretamente a renda, principalmente dos trabalhadores com baixa remuneração salarial e ajudará a combater a inflação.

2. Aumento da carga tributária direta, com a elevação dos tributos sobre a renda, a herança, a riqueza e a propriedade, a exemplo do que ocorre em países como Inglaterra, Alemanha e Estados Unidos. Importante lembrar que o Brasil é um dos países que tem uma das piores distribuições de riqueza do planeta e a diminuição dos tributos indiretos (tributação sobre o consumo) e o aumento dos diretos será um passo determinante para superar essa situação. (GUEDES, 2016,p.247)

Centrado principalmente - não exclusivamente- sobre a tributação sobre o consumo, este artigo busca apresentar um olhar crítico histórico, com observações sobre novos caminhos a trilhar, evitando as distorções do Sistema atual.

O Brasil, entre mais de 100 (cem) países, é o único que ampara uma tributação sobre o consumo com titularidade tripartite (União: IPI, Estados: ICMS, Municípios: ISS).

Partindo deste pressuposto, estudar sobre a tributação sobre o consumo de forma verticalizada, poderia sim, ser uma maneira de se encontrar a solução para minimizar o atual quadro tributário brasileiro.

Para isso, buscou-se, de forma superficial, analisar a atividade financeira do Estado sob a ótica dos tributos, caracterizando o Sistema Tributário Nacional segundo a CF/88, além de se fazer uma breve análise sobre a história da tributação no Brasil e sobre a evolução sobre a tributação sobre o consumo no país. Partimos, assim, deste retrato, mesmo que objetivo, para que, posteriormente, se pudesse conceituar e caracterizar o tributo sobre o consumo, dentro de suas possíveis tipologias, tanto em seu aspecto geral como em seu aspecto jurídico e assim, por fim, relacioná-lo com o atual cenário de turbulência tributária circundada das mais variadas propostas de reforma se seu sistema.

A metodologia empregada vale-se essencialmente de método dogmático-jurídico. Nessa linha, as pesquisas: bibliográfica documental, e legislativa foram essenciais. Como referencial teórico a obra História dos Tributos do Brasil de Cesar Balthazar Ubaldo e Fernando José Amed e Plínio José Labriola de Campos Negreiros.

Justifica-se o estudo do tema pela necessidade de conhecermos o nascimento da tributação no pais, com algumas de suas alterações do decorrer de sua evolução, tendo como referência maior o fato gerador centrado no consumo. 


\section{A ATIVIDADE FINANCEIRA DO ESTAdo NA HISTÓRIA - ENFOQUE NA TRIBUTAÇÃO}

O direito tributário possui, como objetivo central, alcançar o bem-comum da sociedade. Sendo assim, dentre os maiores poderes concedidos pela sociedade ao Estado, para que este fim seja atingido, está o poder de tributar.

Não se sabe exatamente quando e onde a cobrança de tributos começou.

$\mathrm{Na}$ antiguidade os tributos eram obtidos, especialmente, através das colônias. A coroa portuguesa angariava recursos sobre a colônia Brasil por meio da derrama Com a chegada do rei Dom João VI no Brasil, os tributos cobrados eram empregados dentro do nosso próprio país, porém, sua destinação se caracterizava por ser sempre em benefício da família real e, quase nunca em benefício da sociedade brasileira. (BALTHAZAR, 2005, p.15).

Na Europa, no período da Idade Média, marcado pelo Feudalismo, os impostos eram destinados aos senhores feudais, como forma de agradecimento dos servos por poderem usar e morar nos feudos, perdendo assim, os impostos, o seu caráter fiscal. (BALTHAZAR, 2005, p.17).

No final do século XX, surgiu o conhecido Estado Social Fiscal, que dura até os dias atuais e busca amenizar o endividamento legado pelo estado do bem-estar social e, além disso, procura manter o equilíbrio entre a receita e a despesa. (TORRES, 2006, p.173).

As sociedades desde seu princípio sempre necessitaram de certa organização, comando e administração, sendo esse o papel muitas vezes exercido pelo ente do qual se está a falar. Essas funções de organização e regulação da sociedade foram transferidas para o Estado ente extremamente ligado à realização da coisa Pública e proteção dos direitos de seus membros. Nesse sentido Jacques Chevallier refere ser o Estado uma figura necessária à administração e organização da política. (CHEVALLIER, Jacques, 2009,p.184).

Sendo assim, a função basilar do Estado Social Fiscal é a gestão eficiente dos recursos públicos (Responsabilidade Fiscal). Logo, é necessário arrecadar o que tiver de ser arrecadado - permitindo renúncias de receita apenas em caráter de exceção - e manter o maior controle no gasto público. 
Após a independência do Brasil e com o nascimento de sua Constituição Federal, a atividade estatal objetivando uma tributação mais ampla e eficaz passou a denotar uma necessidade corrente e perene.

Com o passar dos anos e, especialmente, com a Constituição Federal de 1988, os tributos, descritos em seus nos artigos 145 a 162, passaram a definir então, as limitações ao poder de tributar do Estado, organizando o sistema tributário brasileiro e detalhando todos os tipos de tributos, bem como, determinando a quem caberia cobrá-los.

Sendo classificados em federais, estaduais e municipais, os tributos para custear as despesas do Estado são por ele mesmo instituídos. A partir disso, em teoria, o Estado, munido do cabedal financeiro carreado pela receita tributária, seria capaz de atingir sua função social.

Esta exação seria, assim, nada mais é do que a atividade exercida pelo Estado para abastecer os cofres públicos. Hugo de Brito Machado define o termo como: “[...] o conjunto de atos que o Estado pratica na obtenção, na gestão e na aplicação dos recursos financeiros de que necessita para atingir seus fins." (MACHADO, 2009, p.12).

\section{PANORAMA SINTÉTICO DO SISTEMA TRIBUTÁRIO NACIONAL SEGUNDO A CF/88.}

Promulgada em 1988, a carta constitucional trouxe, em seu corpo, um capítulo dedicado exclusivamente ao Sistema Tributário Nacional.

Em seus artigos 145 a 162, podemos encontrar, de forma clara, os princípios gerais da tributação nacional, as competências e limitações tributárias dos entes federativos, bem como a repartição das receitas tributárias arrecadadas.

Acreditava-se que estes dispositivos seriam responsáveis por estabelecer a justiça fiscal, diminuindo as desigualdades sociais e permitindo que os entes federativos arrecadassem e conduzisse os recursos recolhidos para os serviços públicos essenciais. 
No ano de 2011 diversos setores econômicos do país, tornaram-se perceptíveis nos Poderes Executivo e Legislativo. (CNI-IBOPE,2016).

Tamanha insatisfação veio comprovar, de forma clara, a necessidade de uma reforma tributária que, entre outros objetivos, resultasse em uma repartição mais justa da carga tributária, considerada, por muitos, como responsável pela sobrecarga nos setores produtivos da economia, contribuindo assim, para uma possível redução na taxa de crescimento nacional.

A tão desejada reforma teria como mote principal a tributação sobre o consumo, considerado, por muitos, ensejadora de disputas entre entes federados (guerra fiscal), injustiça em sua cobrança (regressividade) e distorções em sua quantificação (não cumulatividade parcial).

\section{BREVE HISTÓRICO DA TRIBUTAÇÃO NO BRASIL}

No período das grandes descobertas, que se pautou entre os anos de 1500 e 1532, o primeiro encargo fiscal amparado pelo Brasil foi na indústria extrativa (por meio da extração do pau-brasil).

A coroa portuguesa, ao vislumbrar lucro com a extração vinda pelo cultivo do paubrasil, determinou o início da colonização e o pagamento do quinto do pau-brasil (quinta parte do produto resultante da venda da madeira).

Logo adiante, surgem as capitanias hereditárias. Com o objetivo de proteger as terras recém-descobertas, o Imperador D. João III, decide povoar o Brasil. Para isso, dividiu a parte litorânea do país em quinze partes, destinando-as a donatários. Frisa-se que, nesta época, não havia nenhum tipo de organização fiscal. Sendo assim, os tributos eram pagos in natura, ou seja, em espécie e eram encaminhados para a então metrópole Portugal.

Com o passar do tempo, chegou-se á época do Governo Geral - período este que se compreendeu entre os anos de 1548 a 1763) -, onde os tributos (pagos em produtos in natura) permaneciam sendo cobrados pelos cobradores de rendas. Aqueles que não pagavam pelos tributos ou atrasavam no pagamento dos mesmos, eram presos. Além disso, não havia nenhum tipo de sistema tributário muito menos uma organização fiscal, nesta época. (UBALDO, Cesar Balthazar, 2005). 
Entre os anos de 1808 a 1822, após as tropas de Napoleão invadirem Portugal, a família real portuguesa veio para o Brasil. Instaurou-se assim, um novo período na história do Brasil. Como agora o Brasil passou a ser a sede da monarquia portuguesa, várias leis são criadas.

Em 1808, o Brasil abriu as portas "as nações amigas", autorizando a atividade comercial do país com outros países. Produtos estrangeiros, que até então, tinham sua importação vedada no Brasil, se tornaram, a partir de então, permitidos.

Todo este aparato advindo com a achegada da corte portuguesa em terras brasileiras, fez que com os gastos aumentassem e as despesas para os cofres públicos alavancassem.

Fato este, não dando outra opção à corte, a não ser na instituição e no aumento de novos tributos. Surge, com isso, as taxas.

O Direito Tributário somente foi devidamente fundamentado com a decretação dos Atos Adicional de $1834^{4}$.

Com a evolução do entendimento de Estado e com o surgimento de novas cartas constitucionais, os tributos passaram então a ser definidos tendo em vista o bem-estar social. Sendo assim, foram sendo criadas novas leis para determinar a aplicação social dos recursos arrecadados com os tributos.

Podemos dizer que, nos dias atuais, os tributos são considerados os mais importantes tipos de fontes de arrecadação de receitas públicas de um Estado. A definição e as características deles encontram-se expressamente previsto no Art. 3, CTN. ${ }^{5}$

\section{HISTÓRICO DA TRIBUTAÇÃO SOBRE O CONSUMO NO BRASIL 4.1.1. PERÍODO PRÉ CONSTITUIÇÃo DE 1988}

Pode-se dizer que, até próximo do ano de 1934, a fonte primordial de receita tributária eram os impostos sobre o comércio exterior, principalmente o imposto de importação, sendo

\footnotetext{
${ }^{4}$ O Ato Adicional de 1834 foi uma medida legislativa tomada durante a Regência Trina Permanente, contemplando os interesses dos grupos liberais. O Ato Adicional alterava a Constituição de 1824 e foi uma tentativa de conter os conflitos entre liberais e conservadores nas disputas pelo poder político central.

5 "Art. $3^{\circ}$ Tributo é toda prestação pecuniária compulsória, em moeda ou cujo valor nela se possa exprimir, que não constitua sanção de ato ilícito, instituída em lei e cobrada mediante atividade administrativa plenamente vinculada."
}

Revista Brasileira de Teoria Constitucional | e-ISSN: 2526-0251 | Porto Alegre | v. 4 | n. 2 | p. 22 - 43 | Jul/Dez. 2018 
este, de competência federal. O Imposto de Importação condizia, até o começo da Primeira Guerra Mundial, no entorno da metade da receita total da União, ao passo que, o Imposto de Consumo retratava cerca de $10 \%$ do faturamento. (AMED, Fernando Jose e NEGREIROS, Plínio José Labriola de Campos,2000).

No decurso deste período de guerra, com a minimização dos fluxos de comércio exterior, o governo se viu encarregado a encontrar outras fontes tributárias. Nesta data, existiu uma expansão da participação do Imposto de Consumo e dos Impostos sobre a Renda.

Com o fim da guerra, a receita oriunda do Imposto de Importação se elevou novamente, no entanto não alcançou ao nível alcançado anteriormente.

Ressalta-se também que, no pós-guerra, na esfera estadual, a fonte de receita mais relevante era o Imposto de Exportação, que simbolizava cerca de $40 \%$ da receita estadual. O Imposto de Exportação era obtido nas exportações e nas operações interestaduais. O principal tributo municipal era o Imposto de Indústrias e Profissões e, em seguida, o Imposto Predial. (UBALDO, Cesar Balthazar, 2005).

Após este período, com o advento da Constituição de 1934, os estados conquistaram competência para cobrar o Imposto de Vendas e Consignações (IVC) e, com isso, a alíquota do Imposto de Exportação ficou reduzida a 10\%, sendo censurada a sua exigência em operações interestaduais. Os municípios granjearam poder para instaurar alguns tributos.

A Constituição de 1937 não introduziu modificações marcantes no sistema tributário. Devido às limitações impostas à cobrança do Imposto de Exportação, o IVC transformou-se na principal fonte de receita estadual. No início da década de 1940, o IVC já configurava cerca de $45 \%$ da receita tributária dos estados, ao passo que, o Imposto de Exportação representava apenas 10\%. (UBALDO, Cesar Balthazar, 2005,p. 279).

Com o fim da década de 1930, o Imposto de Consumo veio a ser a mais importante fonte de receita da União. O Imposto de Importação teve sua participação diminuída em decorrência da Segunda Guerra Mundial, deixando de integrar uma fonte significante de receita para a União. Esse imposto tem sido aplicado, desde a década de1950, como ferramenta de política econômica.

A partir da década de 1940, constatou-se o aumento da tributação sobre as bases internas. No ano de 1946, cerca de $40 \%$ da receita tributária da União era advinda através do 


\section{A TRIBUTAÇÃO SOBRE O CONSUMO EM FACE DA TEORIA CONSTITUCIONAL BRASILEIRA: UM CORTE HISTÓRICO SOBRE SUA DOGMATIZAÇÃO IMPOSITIVA}

Imposto de Consumo e quase $30 \%$ pelo Imposto de Renda. (UBALDO, Cesar Balthazar, 2005).

A Constituição de 1946, que tinha como objetivo reforçar as finanças municipais determinou o sistema de transferências de impostos. Aos municípios passou a ser designada a parcela de $10 \%$ da arrecadação do Imposto de Renda e 30\% do excesso sobre a arrecadação municipal, da arrecadação estadual (exceto Imposto de Exportação) no território do município. A receita advinda do Imposto Único sobre combustíveis e lubrificantes, energia elétrica e minerais, de competência federal, passou a ser distribuída com os estados e municípios. O Imposto de Exportação teve sua alíquota máxima limitada a 5\%. (UBALDO, Cesar Balthazar, 2005,p.149).

Em 1961, a Emenda Constitucional no 5 concedeu 10\% da arrecadação do Imposto de Consumo aos municípios e alavancou para $15 \%$ a participação dos municípios na arrecadação do Imposto de Renda. Vale ressaltar que as transferências da receita resultante do Imposto Único eram associadas ao desenvolvimento do sistema de transporte e a empreendimentos relacionados à indústria de petróleo e metade dos recursos do Imposto de Renda destinados aos municípios deveria ser aplicada em benefícios para a população rural. (UBALDO, Cesar Balthazar, 2005).

No início da década de 1960, o Imposto de Consumo retratava aproximadamente 45\% da receita tributária da União, o IVC representava quase $90 \%$ da receita tributária dos estados, e o Imposto de Indústrias e Profissões equivalia a quase $45 \%$ da receita tributária dos municípios. (UBALDO, Cesar Balthazar, 2005,p.152).

O suporte do governo ao progresso econômico e ao desenvolvimento industrial, a partir da década de 1950, ocasionou em um incremento das despesas que não foi assistido pelo aumento das receitas. Com base nisso, a reforma tributária de 1966 buscava restaurar a capacidade de financiamento do Estado; operar o sistema tributário como instrumento do processo de acumulação de capital; e incentivar setores avaliados estratégicos por meio de incentivos fiscais. Sendo assim, o principal objetivo da reforma de1966 era modificar o sistema tributário em um mecanismo capaz de propiciar o equilíbrio orçamentário e fomentar o processo de crescimento econômico.

A preocupação do governo em aumentar as receitas tributárias e lançar empréstimos estava em consonância com o objetivo primeiro de reduzir o déficit do Tesouro. Tudo isso 
deveria ser feito sem que se inflacionasse a moeda brasileira, uma vez que esta era uma das maiores críticas feitas pelo governo militar ao governo constitucional que o antecedeu. (AMED, Fernando Jose e NEGREIROS, Plínio José Labriola de Campos,2000).

Para contribuir com a coordenação do processo de crescimento, procurou-se reunir os fundos na esfera federal. Ante o exposto, era preciso que os impostos sobre o comércio exterior e sobre as operações financeiras, que eram usados como ferramentas de política econômica, fossem de competência do governo federal. Por isso, o Imposto de Exportação deixou de ser de competência estadual. Em consonância, surgiu o Imposto sobre Operações Financeiras (IOF) e o Imposto sobre Transporte e Comunicação, ambos de competência federal. Todavia, procurou-se desenvolver um modelo de federalismo fiscal que assegurasse que os recursos repartidos entre as esferas governamentais fossem colocados de maneira a colaborar com os objetivos nacionais de crescimento e de desenvolvimento industrial.

A grande novidade da reforma de 1966 foi o acolhimento da sistemática de tributação do valor agregado, com a criação do Imposto sobre Circulação de Mercadorias (ICM), de competência estadual, e do Imposto sobre Produtos Industrializados (IPI), de competência federal. O primeiro trocou o IVC, que atingia sobre o faturamento, e o segundo substituiu o Imposto de Consumo, também de natureza cumulativa. O ICM, tendo sido contemplado como um imposto de alíquota uniforme, não interviria na afetação de recursos, inibindo a competição tributária entre os estados. No que diz respeito ao IPI, foi definida uma estrutura de alíquotas diferenciadas de acordo a essencialidade dos produtos, de maneira a tributar mais rigidamente os produtos menos essenciais. (AMED, Fernando Jose e NEGREIROS, Plínio José Labriola de Campos,2000, p.154).

De fato, embora ser um imposto não-cumulativo, o IPI não apresenta traços de um verdadeiro imposto sobre o valor agregado, uma vez que incide somente sobre produtos industrializados.

No âmbito municipal, o Imposto de Indústrias e Profissões foi substituído pelo Imposto sobre Serviços (ISS), o que aumentou a base tributária dos municípios e propiciou uma maior descentralização das responsabilidades públicas. Após a Reforma, os únicos tributos cumulativos eram o ISS e os impostos únicos sobre combustíveis, energia e telecomunicações, de competência federal. 
A Reforma de 1966 simbolizou a progressão do sistema tributário brasileiro e foi amais entranhada reforma ocorrida até hoje no sistema tributário. Vale ressaltar que o Código Tributário Nacional foi promulgado em 1966, malgrado ter sido oriundo de projetos anteriores.

No que diz respeito ao (Imposto sobre Circulação de Mercadorias) ICM, o governo federal determinou uma série de isenções e a não-incidência sobre matérias-primas e equipamentos importados. Ademais, as alíquotas intra e interestaduais sofreram por incessantes reduções. O comércio exterior também foi favorecido por meio de programas como o Benfiex (Benefícios Fiscais a Programas Especiais de Exportação-Brasil), que disponibilizava isenção de tributos indiretos.

Como consequência da concessão de incentivos, a receita do governo começou a se corromper e para solver esse problema foi criado, em 1970, o Programa de Integração Social (PIS), tributo cumulativo incidente sobre o faturamento mensal das empresas. Também foi criado, em 1970, o Programa de Formação do Patrimônio do Servidor Público (PASEP), financiado pela contribuição mensal de entidades de natureza pública. A criação do PIS/PASEP reintroduziu a cumulatividade, modificando o processo de modernização do sistema tributário. Em 1982, a criação da contribuição para Fundo de Investimento Social (Finsocial), também de natureza cumulativa piorou ainda mais este quadro.

A Constituição de 1967 revolucionou o sistema tributário nacional, mas firmou-se na centralização das receitas e despesas no governo federal, intervindo na autonomia dos estados e municípios. O poder dos estados para legislar sobre o ICM foi restringido e, logo após a reforma, foram diminuídas as transferências da receita do Imposto de Renda e do IPI para os Fundos de Participação dos Estados e dos Municípios. Os estados e os municípios enfrentaram ao baixo grau de autonomia que lhes foi atribuído, o que deu ensejo às Emendas Constitucionais $n^{\circ} 5 / 75, n^{\circ} 17 / 80$ e $n^{\circ} 23 / 83$, que alavancaram com os percentuais de transferência de recursos para os estados e municípios. (AMED, Fernando Jose e NEGREIROS, Plínio José Labriola de Campos,2000,p.169).

\subsubsection{A CONSTITUIÇÃO DE 1988}


O objetivo primordial da Constituição de 1988 foi a consolidação da Federação; e, com isso, o aumento da autonomia fiscal dos entes federativos e a descentralização dos recursos tributários. Logo, providenciaram-se a extensão do campo de competência dos governos subnacionais e a ampliação dos percentuais da apuração do Imposto de Renda e do IPI destinados aos Fundos de Participação dos Estados e dos Municípios, com a desligamento das receitas transferidas (à exceção dos recursos direcionados para a educação).

Buscou-se também aumentar a função social do governo, o que se repercutiu na divulgação do acesso à previdência, na amplificação dos gastos com a saúde e dos programas de assistência. Sendo assim, os gastos sociais do governo federal alavancaram ao mesmo tempo em que se prosperou a descentralização das receitas públicas em face dos governos subnacionais. Porém, não foi desenvolvido um processo de descentralização das responsabilidades públicas, principalmente na área das políticas sociais. $O$ efeito da introdução desse modelo foi a separação entre recursos arrecadados e responsabilidades públicas.

Os impostos sobre energia elétrica, combustíveis e lubrificantes, serviços de comunicações e de transporte interestadual, que eram de competência federal, foram anexados à base de incidência do ICM, que passou a ser chamado de (Imposto sobre Circulação de Mercadorias e Serviços) ICMS.

Complementarmente, foi vedada a transferência de isenções de impostos estaduais e municipais pela União.

A base de incidência do ISS foi ampliada, com o aumento da lista de serviços tributados e ainda houve o aumento do percentual da arrecadação do ICMS transferido pelos estados aos Municípios. Os Municípios foram os maiores beneficiados com as transferências constitucionais, que proporcionaram um aumento expressivo nas receitas municipais.

Por meio da Constituição de 1988, os governos subnacionais angariaram competências tributárias exclusivas e autonomia para legislar, arrecadar, administrar e gastar os recursos. Os estados contraíram competência para consolidar as alíquotas internas do ICMS, que passaram a ser expressas pelos regulamentos do ICMS de cada estado, desde que fossem superiores às alíquotas interestaduais. As alíquotas utilizadas nas operações interestaduais e nas exportações, assim como as alíquotas máximas nas operações internas, seriam deliberadas pelo Senado. 
Até que fosse aprovada a Lei Complementar que regulamentaria o ICMS, o Conselho de Política Fazendária (CONFAZ), órgão formado pelos secretários de fazenda estaduais, recebeu amplos poderes regulatórios ${ }^{6}$. Foi mantida a incidência do ICMS sobre as exportações de produtos primários e ampliou-se a incidência para os produtos semielaborados, com o fim de proteger os estados menos industrializados. As exportações de produtos industrializados ficaram isentas, tendo sido criadas compensações fiscais para os estados exportadores.

Por meio do aumento da base de incidência do antigo ICM e do ISS, ocorreu a expansão da participação dos estados e municípios na receita tributária e a consecutiva diminuição da União. Como não existiu, em consonância, um processo de descentralização de encargos, foi realizada um conjunto de medidas com o intuito de resolver o desequilíbrio fiscal e financeiro da União.

Sabendo que a receita dos principais impostos federais era dividida com os governos estaduais e municipais, a União assentou explorar impostos e contribuições cuja receita não seria repartida com os governos subnacionais. Com base nisso, surgiu a Contribuição Social sobre o Lucro Líquido (CSLL), em 1989, e o Imposto Provisório sobre Movimentação Financeira (IPMF), em 1993.

Vale dizer que, também houve o aumento, em 1990, das alíquotas do Imposto sobre Operações Financeiras (IOF) e da Contribuição para o Financiamento da Seguridade Social (COFINS), antigo Finsocial.

As novas contribuições sociais nasceram com o objetivo de modificar os alicerces de financiamento da seguridade social, que submetia basicamente das contribuições incidentes sobre a folha de salários.

$\mathrm{Na}$ busca do alargamento da base imponível, as contribuições, que anteriormente incidiam apenas sobre os salários, passaram a incidir sobre a receita e sobre o lucro das empresas.

\footnotetext{
${ }^{6}$ O CONFAZ-CONSELHO NACIONAL DE POLÍTICA FAZENDÁRIA foi criado pela Lei Complementar $\mathrm{n}^{\circ}$ 24/75 com a finalidade de regulamentar, de forma consensual, os tratamentos especiais concedidos no âmbito do ICMS.
} 
Enquanto uma parcela da arrecadação dos impostos federais devia ser repassada para os Estados e Municípios, não havia nenhuma exigência quanto à repartição das receitas provenientes das contribuições sociais.

Nesta época, os países desenvolvidos viviam por um período de reavaliação da estrutura tributária, em que almejavam acabar com os efeitos dos tributos sobre bens e serviços na competitividade do setor produtivo.

Contrário a este processo, acontecia no Brasil o aumento da tributação cumulativa, piorando as distorções do sistema tributário nacional. Verifica-se, assim, que a Constituição de 1988 ao buscar estimular a federação e alavancar os direitos sociais comprometeu a qualidade do sistema tributário nacional.

No ano de 1996, foi instituída a Lei Complementar nº87, conhecida como Lei Kandir ${ }^{7}$, que isentava do ICMS as exportações de bens primários e semielaborados. Cabe ressaltar que as exportações de produtos industrializados já não eram tributadas pelo imposto. A Lei Kandir também desonerou da cobrança do ICMS as aquisições de bens de capital. Com a desoneração das exportações e das aquisições de bens de capital, o ICMS adquiriu características que o aproximaram de um IVA-Consumo, tipo de IVA que onera unicamente o consumo.

As perdas de arrecadação incorridas pelos estados em função da desoneração das exportações passaram a ser ressarcidas pelo Tesouro Nacional. No entanto, argumentava-se que as transferências federais não compensavam a perda de receita tributária e os critérios de repasse vinculados à Lei Kandir passaram a ser constantemente questionados pelos governadores.

Pondera-se, inclusive, justamente o aumento das exportações nacionais justificaria a ampliação dos repasses da União aos Estados.

Outra medida importante foi a edição da Lei ${ }^{\circ}$ 9.363/96, que instituiu o ressarcimento aos exportadores do PIS e da COFINS incidentes sobre os insumos utilizados na fabricação do bem exportado. O ressarcimento se daria através da compensação com débitos do IPI. Convém ainda acrescentar a criação, em 1996, do regime simplificado para micro e pequenas

\footnotetext{
${ }^{7}$ A Lei Kandir, lei complementar brasileira ${ }^{\circ} 87$ que entrou em vigor em 13 de setembro de 1996 no Brasil, dispõe sobre o imposto dos estados e do Distrito Federal, nas operações relativas à circulação de mercadorias e serviços (ICMS). A lei Kandir isenta do tributo ICMS os produtos e serviços destinados à exportação. A lei tem este nome em virtude do seu autor, o ex-deputado federal Antônio Kandir.
} 


\section{A TRIBUTAÇÃO SOBRE O CONSUMO EM FACE DA TEORIA CONSTITUCIONAL BRASILEIRA: UM CORTE HISTÓRICO SOBRE SUA DOGMATIZAÇÃO IMPOSITIVA}

empresas $\left(\right.$ Simples) ${ }^{8} \mathrm{e}$ da Contribuição Provisória sobre as microempresas e empresas de pequeno porte, denominado Simples Nacional ou Super Simples.

Movimentação Financeira (CPMF), destinada ao financiamento da saúde ${ }^{9}$, a CPMF foi criada com alíquota de $0,20 \%$ e com prazo de duração previsto para 13 meses.

A partir de 1999, teve início o processo de ajuste fiscal, tendo sido estabelecidas metas de superávit primário para setor público, incluindo governo federal, governos subnacionais e empresas estatais. Na década de 2000, o ajuste fiscal perseguido desde o início do Plano Real foi alcançado com o aumento significativo da carga tributária global. Esse aumento ocorreu através das contribuições sociais cumulativas, as quais, além de não serem compartilhadas com os estados e municípios, apresentam elevado potencial de arrecadação e fácil administração. A elevação da carga tributária permitiu o cumprimento das metas de superávit primário necessárias para custear o serviço da dívida e também permitiu atender às demandas por maiores gastos com programas sociais.

No Brasil, bem como em outros países, a tributação ocorre de três formas, tendo como base imponível, basicamente, o patrimônio, renda e consumo.

Como temos como objeto do referido artigo a tributação sobre o consumo, poderíamos dizer que esta tributação apresenta como uma de suas principais características a sua repercussão econômica na cadeia de consumo, de maneira que se opera a transferência do ônus tributário ao consumidor final por meio da vinculação do tributo no preço do bem ou serviço, como um custo extra.

Com isso, acontece uma ruptura entre o contribuinte de direito, previsto na lei como sendo o responsável pelo fato tributável e que ocupa, dessa forma, o polo passivo da obrigação tributária, e aquele que arca economicamente com a obrigação em si, conhecido pela doutrina e jurisprudência por contribuinte de fato.

Pode-se dizer que, o tributo sobre o consumo é o principal tributo brasileiro, que acaba por incidir em diversas etapas do processo produtivo de bens e serviços e entre as bases de incidência dos tributos, patrimônio, renda e consumo, esta última simboliza a maior parte da arrecadação tributária.

\footnotetext{
${ }^{8}$ O Simples foi extinto em 2007 pela Lei Complementar no $123 / 06$, a qual instituiu um novo regime para ${ }^{9}$ A CPMF substituiu o IPMF.
}

Revista Brasileira de Teoria Constitucional | e-ISSN: 2526-0251 | Porto Alegre | v. 4 | n. 2 | p. 22 - 43 | Jul/Dez. 2018 
Com base em informações adquiridas pela $\operatorname{OCDE}^{10}$ (Organização para Cooperação e Desenvolvimento Econômico) a carga tributária brasileira sobre o patrimônio simboliza $3,52 \%$, sobre a renda $24,14 \%$, e sobre o consumo $68,20 \%$. Ainda há uma parte que é da seguridade social, que não pode ser entendida como base de incidência, mas que, embora assim seja, ainda é repassada para o consumidor.

No Brasil, a tributação sobre o consumo é composta principalmente por três impostos: o Imposto sobre Produtos Industrializados (IPI), o Imposto sobre a Circulação de Mercadorias e Serviços de Transporte Interestadual e Intermunicipal e de Comunicação (ICMS) e o Imposto Sobre Serviços de Qualquer Natureza (ISS).

Ressalta-se que cada um desses impostos é de competência de uma entidade política distinta e incide, de algum modo, sobre o consumo de bens e serviços em nosso país.

O IPI, o ICMS e o ISS, de competência respectiva da União, Estados e Municípios, podem ser interpretados como "típicos" tributos sobre o consumo. Frisa-se que, existem outros tributos e outras espécies tributárias que incidem sobre o consumo, porém estes são os mais relevantes.

Em resumo, como a principal característica da tributação sobre o consumo é que ela é uma tributação indireta que interfere em toda cadeia de consumo, podemos concluir que recai sobre o contribuinte todo o custo operacional de bens ou serviços.

Assim denomina-se aquele que realmente suporta o custo adicional o contribuinte de fato, "nós, consumidores", diferentemente do contribuinte de direito previsto no ordenamento jurídico como responsável pelo fato imponível que ocupa o polo passivo da obrigação tributária.

Percebe-se, inclusive, como a tributação pode levar a uma carga tributária desigual e, portanto, injusta. ${ }^{11}$

${ }^{10}$ Dados relativos ao exercício fiscal de 2008. Para maiores informações, ver OCDE Revenue Statistics (19652008).

${ }^{11}$ Pedro é atendente e recebe 1.000,00 por mês. Sua renda não é tributável pelo imposto de renda. Com esse salário, Pedro, possivelmente não deve ter uma casa confortável o suficiente, porém paga IPTU, paga também ICMS dos produtos que compra no supermercado etc. Tudo com esse salário.

Agora lhes apresento o Guilherme. Guilherme é gerente administrativo de uma grande empresa. Ganha 17.500,00 por mês. Sua renda será tributada pelo Imposto de Renda IR em 27,5\%. Com esse salário pode-se considerar que Pedro possui bens, casa confortável, carro, etc.

Revista Brasileira de Teoria Constitucional | e-ISSN: 2526-0251 | Porto Alegre | v. 4 | n. 2 | p. 22 - 43 | Jul/Dez. 2018 


\subsection{O QUE ESPERAR DA TRIBUTAÇÃO SOBRE O CONSUMO NO BRASIL?}

Nem todos sabem, mas a grande verdade é que, a crise fiscal em que estamos vivendo, pode ser uma boa oportunidade de se ponderar os erros cometidos no passado para que possamos corrigir distorções e buscar uma carga tributária mais equilibrada, justa e racional.

Já se é sabido que precisamos de medidas que minimizem a carga tributária para que, juntamente, com outras medidas, o Brasil retome seu crescimento econômico.

Muitos colocam a culpa deste quadro atual no Estado, que arrecada muito e gerencia mal os recursos em que recebe.

No último ano, foi anunciado um modelo de reforma tributária traçada na "simplificação do sistema de arrecadação" e "diminuição do tempo de criação de novas empresas". Simplificar a cobrança dos tributos é uma demanda que não é de hoje. Desde os anos quarenta em que a base da tributação brasileira deixa de ser os tributos sobre a importação para incidir mais fortemente sobre o consumo interno, a complexidade do sistema arrecadatório tem sido um problema. Ao longo desses anos as medidas de simplificação duraram pouco tempo e logo são substituídas pelos controles arrecadatórios e o sistema volta a ficar complexo e caro.

A Câmara dos Deputados discutiu então sobre uma proposta de reforma tributária em que a cobrança de impostos seria concentrada mais na renda do que no consumo.

O Sistema Tributário Brasileiro se resume na arrecadação sobre o consumo em vez da renda, um arquétipo que sobrecarrega e penaliza os mais pobres, recebendo críticas generalizadas por ser burocrático, confuso e de custo alto para governo e empresas.

A proposta unifica impostos e simplifica a legislação com um objetivo: não aumentar a carga tributária. $\mathrm{O}$ aumento sobre a renda e o patrimônio seria compensado por uma redução na carga tributária sobre o consumo.

O Brasil, além de evidenciar o vergonhoso posto de país com elevadíssima concentração de renda e baixíssimos índices de equidade social, autoriza que o seu sistema

Visualize agora os dois no mesmo supermercado fazendo compras. Fará alguma diferença se Guilherme ou Pedro comprarem a mesma mercadoria? Ou Pedro pagará menos tributo porque ganha menos que Guilherme? Não. Os dois irão pagar exatamente a mesma carga tributária sobre o produto que levarem. Aí que mora a injustiça social tributária.

Revista Brasileira de Teoria Constitucional | e-ISSN: 2526-0251 | Porto Alegre | v. 4 | n. 2 | p. 22 - 43 | Jul/Dez. 2018 
tributário disponibilize auxílios precisos no avanço desses problemas. Com base nas informações do IPEA $^{12}$, em 1996, as pessoas com renda de até 2 salários mínimos comprometiam $28,2 \%$ de sua renda com pagamento de tributos, na contramão os que ganhavam mais de 30 salários somente 17,9\%.

Em 2004, essa divergência incrementou, respectivamente, para 48,8\% e 26,3\% e, no ano de 2008 , migrou para $53,9 \%$ e $29 \%$. Esse resultado, contrário do que se espera de um sistema de tributação equitativo, recebe o nome de "regressividade".

Desde Adam Smith ${ }^{13}$ (1723-1790), contempla-se o argumento de que uma teoria de tributação equitativa se desenrola dos princípios da "equidade vertical", de maneira que o sistema de tributação deve projetar mecanismos que possibilitam aos que ganham mais pagarem mais tributos do que os que têm uma renda menor.

Esse absurdo do sistema tributário brasileiro é praticamente fomentado pela forte carga tributária sobre o consumo de bens e serviços (cerca de $20 \%$ do PIB), contra uma carga fiscal escassa sobre propriedade e renda (aproximadamente 7\% do PIB). Os tributos sobre o consumo são desleais, visto que incidem sobre o rico e o pobre sem diferenciar a renda de um e de outro.

Apreciados os tributos do consumo, o fardo da tributação sobre as necessidades básicas como as de comer, cuidar da saúde, vestir, morar e estudar são proporcionalmente mais altas para o pobre do que para o rico.

Nos países da $\mathrm{OCDE}^{14}$, a média da tributação sobre o consumo é de $11,5 \%$ e sobre renda e propriedade cerca de $13 \%$.

\footnotetext{
12 IPEA: A fundação Instituto de Pesquisa Econômica Aplicada é uma fundação pública federal vinculada ao Ministério do Planejamento, Orçamento e Gestão criada em 1964 como Epea e assumindo o nome atual em 1967.

13 Adam Smith foi um filósofo e economista britânico nascido na Escócia. Teve como cenário para a sua vida o atribulado século das Luzes, o século XVIII. É o pai da economia moderna, e é considerado o mais importante teórico do liberalismo econômico.
}

14 A Organização para a Cooperação e Desenvolvimento Econômico (OCDE) é uma organização internacional de 35 países que aceitam os princípios da democracia representativa e da economia de mercado, que procura fornecer uma plataforma para comparar políticas económicas, solucionar problemas comuns e coordenar políticas domésticas e internacionais. A maioria dos membros da OCDE é composta por economias com um elevado PIB per capita e Índice de Desenvolvimento Humano e são considerados países desenvolvidos. 


\section{A TRIBUTAÇÃO SOBRE O CONSUMO EM FACE DA TEORIA CONSTITUCIONAL BRASILEIRA: UM CORTE HISTÓRICO SOBRE SUA DOGMATIZAÇÃO IMPOSITIVA}

Clamamos por um nível de igualdade e de desenvolvimento humano da Dinamarca que taxa somente a renda a $40 \%$ em relação ao PIB - praticando índices tributários abaixo da média dos países desenvolvidos. Com exceção, evidentemente, da tributação sobre o consumo, da qual o Brasil é o país recordista.

A reforma tributária de que o país demanda emergencialmente não é a da simplificação do sistema, mas a desejada "justiça tributária", em padrões mais imparciais, a minimizar os impactos regressivos do nosso sistema de tributação.

Se a proposta de reforma se concretizar, a cobrança dos impostos passaria a ser online, na hora em que se efetua a compra pela mercadoria. $O$ dinheiro seria separado e enviado concomitantemente para os cofres públicos, o que reduziria a sonegação.

Além disso, segundo o Centro de Estudos Tributários e Financeiros Consultoria e Pesquisa de Interesse Público Limitada $(\mathrm{CCiF})^{15}$, o cerne da proposta é a substituição de cinco tributos atuais - PIS, Cofins, IPI, ICMS e ISS - por um único imposto do tipo IVA ${ }^{16}$, denominado Imposto sobre Bens e Serviços - IBS, cujas características refletem as melhores práticas internacionais.

A proposta de migração do modelo brasileiro de tributação de bens e serviços para um modelo do tipo IVA, que busca aproximar o Brasil do praticado no resto do mundo, nada tem de original. Esta proposta vem sendo defendida por vários especialistas pelo menos desde meados dos anos 1980. (Centro de Estudos Tributários e Financeiros Consultoria e Pesquisa de Interesse Público Limitada, 2017).

Uma outra mudança relevante seria que os remédios, alimentos, máquinas e equipamentos não pagariam o IVA. E, acompanhando a tendência mundial, os produtos de exportação também ficariam isentos de impostos.

O imposto de renda passaria por uma significativa restruturação. Integraria a contribuição sobre o lucro líquido das empresas e desenvolveria um peso maior sobre os mais ricos.

É importante notar que o modelo proposto não é uma proposta fechada, mas sim uma contribuição para o debate sobre o aprimoramento do sistema tributário do país, que também

\footnotetext{
${ }^{15} \mathrm{O}$ Centro de Cidadania Fiscal é um think tank independente que tem como objetivo contribuir para a simplificação do sistema tributário brasileiro e para o aprimoramento do modelo de gestão fiscal do país.

${ }^{16}$ Imposto sobre Valor Agregado visa reduzir a burocracia brasileira ao adotar um tributo geral sobre o consumo que substitua o PIS, o Cofins e o IPI (tributos federais); o ISS (tributo municipal); e até o ICMS (tributo estadual).
}

Revista Brasileira de Teoria Constitucional | e-ISSN: 2526-0251 | Porto Alegre | v. 4 | n. 2 | p. 22 - 43 | Jul/Dez. 2018 
pode ser melhorada. O próprio CCiF (Centro de Cidadania Fiscal) segue discutindo alguns detalhes técnicos da proposta e irá divulgar notas técnicas à medida em que avançar nesses estudos. (Centro de Estudos Tributários e Financeiros Consultoria e Pesquisa de Interesse Público Limitada, 2017).

Os benefícios esperados das mudanças propostas são muitos. Por um lado, a grande simplificação do modelo de tributação de bens e serviços contribuiria para redução expressiva do custo de conformidade tributária (custo de compliance), bem como do litígio sobre matéria tributária. Em particular, a simplificação poderia até permitir o lançamento de ofício do imposto para os contribuintes de menor porte, que teriam como obrigação apenas o registro de compras e vendas através do sistema de nota fiscal eletrônica. No agregado, a mudança representaria uma expressiva melhora do ambiente de negócios do país. (Centro de Estudos Tributários e Financeiros Consultoria e Pesquisa de Interesse Público Limitada, 2017).

Por outro lado, as mudanças propostas tendem a contribuir para a ampliação da taxa de investimento de duas formas: pela redução do custo dos bens de capital (resultado da eliminação da cumulatividade); e pelo aumento da segurança jurídica das empresas, consequência da grande simplificação do sistema tributário. (Centro de Estudos Tributários e Financeiros Consultoria e Pesquisa de Interesse Público Limitada, 2017).

Por fim, o governo federal, estados e municípios passariam a repartir impostos que hoje são exclusivos de um deles, o que sempre ocasionou embates políticas. A reforma, sem sombra de dúvidas, ajudaria na recuperação do crescimento do país.

\section{CONCLUSÃO}

Quando tratamos de tributos no Brasil, se faz indispensável, para que tenhamos uma visão mais segura e precisa sobre seu uso, termos que fazer um apanhado histórico de sua criação.

Se não sabemos de onde surgiram e como surgiram, não se faz razoável, então, traçar um desenho de sua estrutura seja nas diversas espécies tributárias que se apresentam seja na distribuição de competências dos entes federados; não olvidando, inclusive, a repartição de receitas decorrente do pacto federativo mormente naquelas Constituições tidas como democráticas. 


\section{A TRIBUTAÇÃO SOBRE O CONSUMO EM FACE DA TEORIA CONSTITUCIONAL BRASILEIRA: UM CORTE HISTÓRICO SOBRE SUA DOGMATIZAÇÃO IMPOSITIVA}

Neste sentido, buscou-se, nos limites possíveis estabelecidos, apresentar um quadro histórico da tributação nacional e, na sequência, dando-se um olhar mais cuidado na denominada tributação sobre o consumo. Esta materialidade de incidência tributária, em suas várias vertentes, nos despertou uma preocupação diferenciada já que representativa da maior distorção de todo os sistemas, seja no seu aspecto funcional, inibidor econômico, de competência ou mesmo de sua decantada regressividade a penalizar as camadas mais carentes da sociedade.

Por fim, apresentamos um pequeno excerto de ponderações de possíveis caminhos a trilhar, sabedores dos inúmeros óbices a serem enfrentados já que qualquer alteração de sua estruturação exigiria um repensar de todo o sistema tributária e do próprio papel do Estado como entidade agregadora social e executor de múltiplas tarefas cuja dimensão e abrangência cada vez mais são objeto de questionamentos.

Tratar a tributação sobre o consumo, já que representa o maior quinhão sobre o bolo tributário, é, indubitavelmente, discutir quem pagar a maior fatura bem como o quanto se paga para justificar o tamanho do Estado, em seus vários níveis, e sua existência enquanto organismo de sustentação social.

\section{REFERÊNCIAS BIBLIOGRÁFICAS}

AMED, José Fernando e NEGREIROS, Plínio José Labriola de Campos. História do Tributo no Brasil.São Paulo: Sinasfresp. 2000.

BALTHAZAR, Ubaldo César. História do Tributo no Brasil. 2005.

BRASIL. Código Tributário Nacional. São Paulo: Saraiva, 2015;

BRASIL. Constituição da República Federativa do Brasil. São Paulo: Saraiva, 2015;

BRASIL. Lei Complementar no 123, de 14 de dezembro de 2006. Institui o Estatuto Nacional da Microempresa e da Empresa de Pequeno Porte; altera dispositivos das Leis nos 8.212 e 8.213, ambas de 24 de julho de 1991, da Consolidação das Leis do Trabalho - CLT, aprovada pelo Decreto-Lei no 5.452, de 1 o de maio de 1943, da Lei no 10.189, de 14 de fevereiro de 2001, da Lei Complementar no 63, de 11 de janeiro de 1990; e revoga as Leis nos 9.317, de 5 de dezembro de 1996, e 9.841, de 5 de outubro de 1999.

Revista Brasileira de Teoria Constitucional | e-ISSN: 2526-0251 | Porto Alegre | v. 4 | n. 2 | p. 22 - 43 | Jul/Dez. 2018 
CARF. Disponível em: <http://carf.fazenda.gov.br/sincon/public/pages/index.jsf>. Acesso em:04.05.16;

Centro de Estudos Tributários e Financeiros. Reforma do Modelo de tributação de bens e serviços. Agosto de 2017.

CNI-IBOPE. Disponível em: http://www.fiepr.org.br/sombradoimposto/pesquisa-mostrainsatisfacao-dos-brasileiros-1-14466-131813.shtml. Acesso em 18/03/2017.

CHEVALLIER, Jacques. O Estado Pós-moderno. Trad. Marçal Justen Filho. Belo Horizonte: Fórum, 2009.

GUEDES, Odilon. Disponível em: http://www.psol50.org.br/blog/2016/12/15/odilon-guedesreforma-tributaria-e-a-solucao-para-a-crise-fiscal-do-estado-brasileiro/. Acesso em 17/3/17). MACHADO, Hugo de Brito. Curso de Direito Tributário, São Paulo: Malheiros Editores, $12^{\mathrm{a}}$. ed., 1997.

TORRES, Ricardo Lobo. A ideia de Liberdade no Estado Patrimonial e no Estado Fiscal. Rio de Janeiro: Ed. Renovar, 1991. 